\title{
Artificial Neural Network Modeling and Mechanism Study for Relaxation of Deformed Rubber
}

\author{
Xiu-Juan Wang, ${ }^{1,2}$ Xiu-Ying Zhao, ${ }^{1,2}$ Qiang-Guo Li, ${ }^{1,2}$ Tung W. Chan, ${ }^{3}$ and Si-Zhu Wu ${ }^{1,2 *}$ \\ ${ }^{1}$ State Key Laboratory of Organic-Inorganic Composites, Beijing University of Chemical \\ Technology, Beijing 100029, P.R. China \\ ${ }^{2}$ Engineering Research Center of Elastomer Materials Energy Conservation and Resources, \\ Ministry of Education, Beijing University of Chemical Technology, Beijing 100029, China \\ ${ }^{3}$ Department of Materials Science and Engineering, Virginia Polytechnic Institute and
}

State University, Blacksburg, VA 24061, USA

\section{Author Information}

Corresponding Author

*Email:wusz@mail.buct.edu.cn, Tel: 86-010-6444923. 


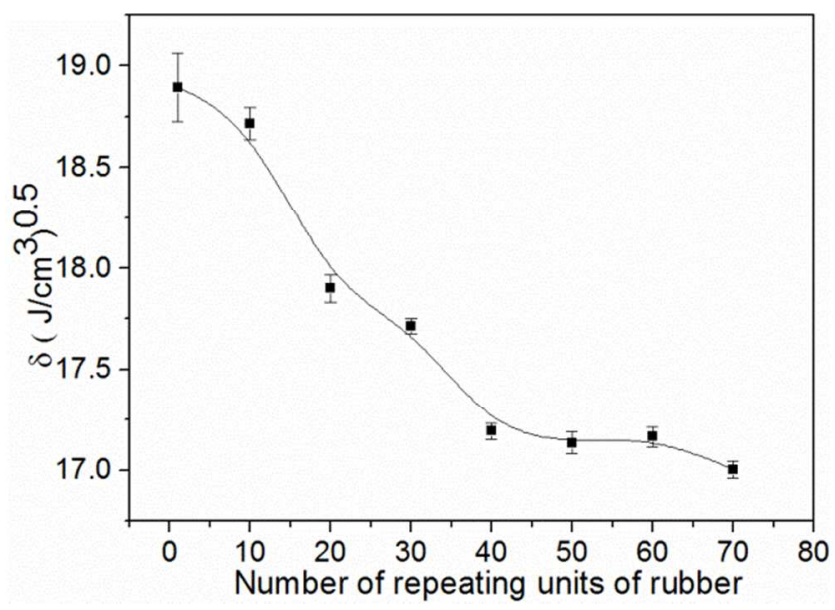

Figure S1. Simulated solubility parameter $(\delta)$ of NR versus number of repeating units.

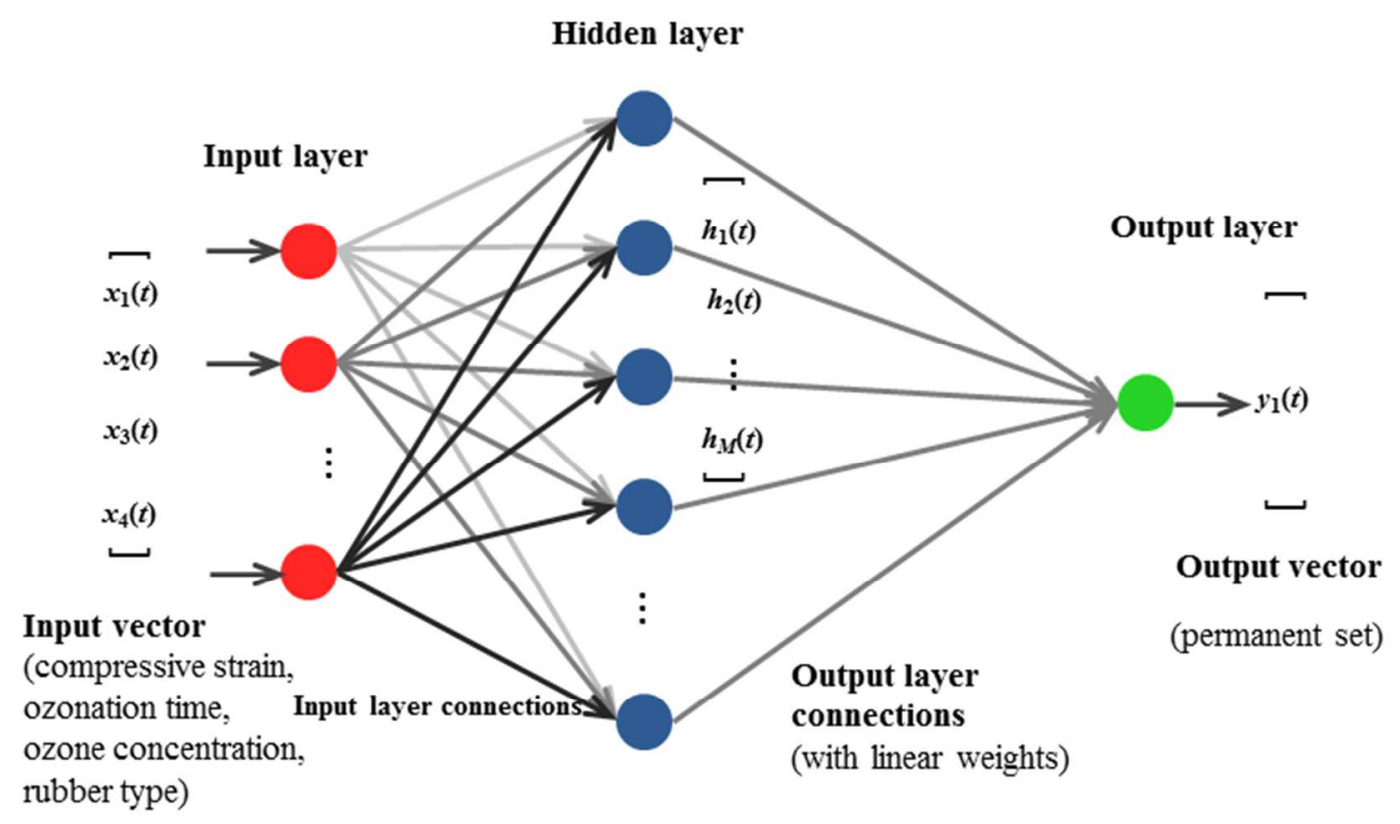

Figure S2. Structure of RBF artificial neural network.

Table S1. Parameters of the Model after Equilibration at $298 \mathrm{~K}$

$\begin{array}{ccccccc}\begin{array}{c}\text { Rubber } \\ \text { model }\end{array} & \rho_{\text {sim }}\left(\begin{array}{l}\mathrm{g} \mathrm{cm}^{-} \\ \mathrm{cm}^{-}\end{array}\right. & \rho_{\exp }\left(\mathrm{g} \mathrm{cm}_{3}^{-}\right. & \delta_{\mathrm{sim}_{3}}\left(\mathrm{~J} \mathrm{~cm}^{-}\right. & \delta_{\exp _{3}}\left(\mathrm{~J} \mathrm{~cm}_{0.5}^{-}\right. & \begin{array}{c}\text { Number of } \\ \text { atoms }\end{array} & \begin{array}{c}\text { Cell edge } \\ (\AA)\end{array}\end{array}$

NR

0.90

0.93

17.3

$17.0^{3}$

3260

30.95

Table S2. Recipes of Rubber Composites 


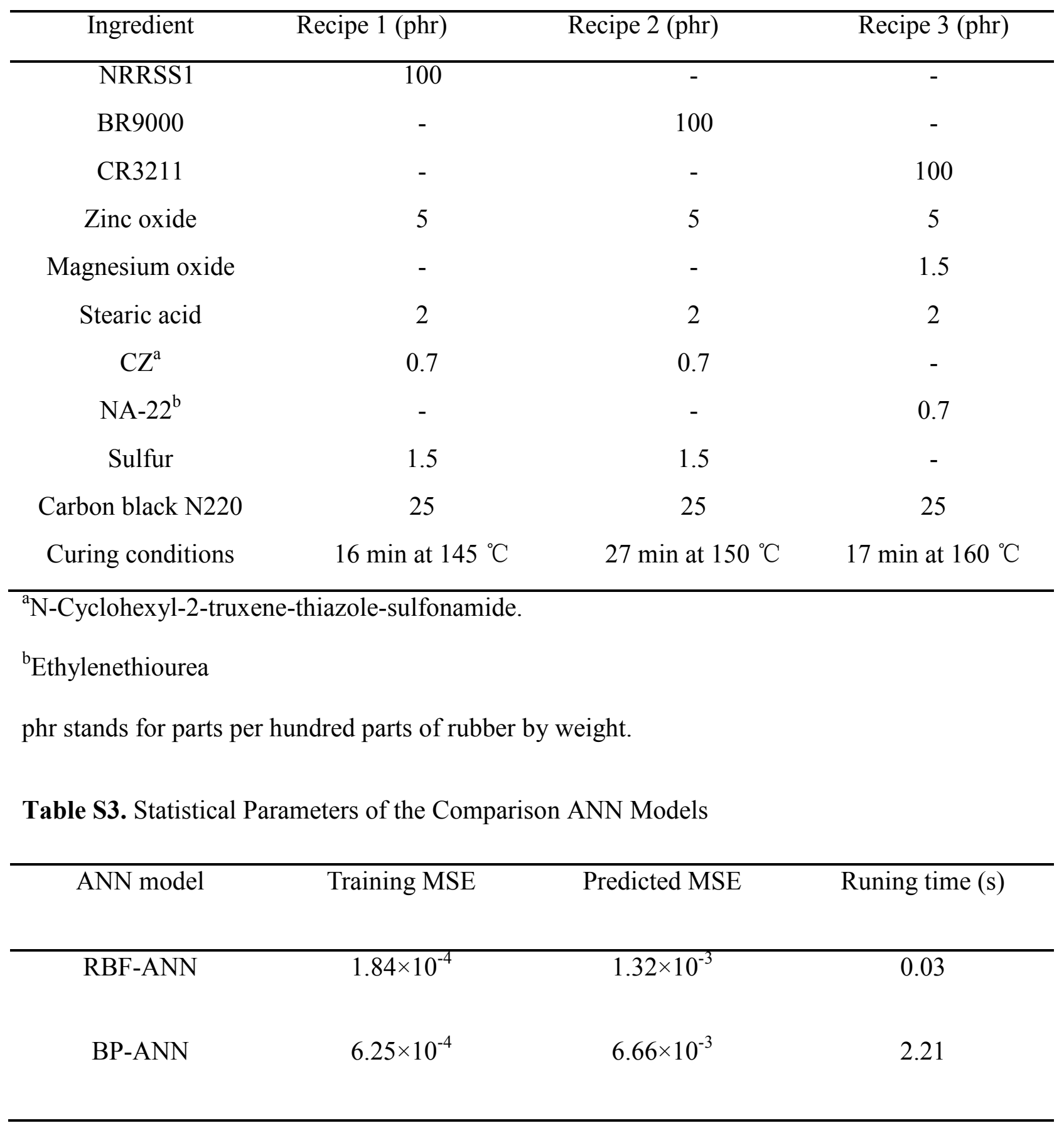

